\title{
DAMPAK EKONOMI ASEAN CHINA FTA TERHADAP PRODUK ELEKTRONIK INDONESIA
}

\section{The Economic Impact of ASEAN China FTA to Electronic Products Indonesia}

\author{
Aziza R Salam dan Bagas Haryotejo \\ Pusat Kebijakan Perdagangan Dalam Negeri dan Luar Negeri Kementerian Perdagangan \\ e-mail: thenayu78@yahoo.com
}

Diajukan: 3 Oktober 2011, Dinilaikan: 4 Oktober 2011; Diterima: 28 November 2011

\begin{abstract}
Abstrak
ASEAN-China Free Trade Area (AC-FTA) merupakan kerjasama perdagangan bebas antara negara-negara anggota ASEAN dengan China mengenai penurunan tarif bea masuk dan pajak. Secara otomatis harga barang yang diimpor dari China akan lebih murah karena tidak ada lagi tarif yang menjadi biaya bagi para importir. Dalam rangka menanggulangi banjirnya produk impor China, pemerintah Indonesia menerapkan instrument non-tariff barrier, dalam hal ini antara lain SNI (Standar Nasional Indonesia). Sampai saat ini, masih ditemukannya kasuskasus yang terkait dengan kualitas produk China yang rendah, khususnya produk elektronik. Berdasarkan analisa, setelah adanya kesepakatan ASEAN-China FTA, produk China yang sering dibeli adalah elektronik (34\%), telepon seluler (19\%), mainan anak $(11,1 \%)$, alat rumah tangga non elektronik $(9,9 \%)$, pakaian/tekstil $(9,3 \%)$ dan selebihnya tas dan sepatu, alat transportasi, serta komputer dan perlengkapan. Hal ini sesuai dengan pandangan bahwa salah satu produk China yang dapat membanjiri pasar dalam negeri dan menggerus industri lokal adalah produk elektronik yang dinilai relatif berdaya saing dengan harga jual yang murah. Untuk beberapa Produk, SNI yang diberlakukan cukup efektif, namun untuk sebagian besar produk elektronik SNI masih belum efektif, hal ini ditunjukan oleh meningkatnya impor setelah diberlakukannya kebijakan SNI. Sedangkan Akibat adanya perjanjian ASEAN-China FTA, penerimaan negara berkurang sebesar 546.146 ribu US\$, penerimaan negara terbesar yang hilang adalah dari HS 841451. Dengan adanya penerapan perjanjian ASEAN-China FTA, Indonesia mendapatkan keuntungan kesejahteraan nasional sebesar 98,445 (ribu US\$). Berdasarkan hasil simulasi, baik terhadap Penerimaan negara maupun Kesejahteraan dengan besaran masing-masing $(-546.146)$ ribu US\$, dan 98.445 ribu US\$, dapat disimpulkan bahwa dengan adanya Perjanjian Kerjasama ASEAN-China, Indonesia mengalami kerugian ekonomi sebesar 447.701 ribu US\$ (revenue + welfare) dari sektor EEE (Electric and Electronic Equipment).
\end{abstract}

Kata kunci: SNI, Elektronik, ASEAN-China FTA

\begin{abstract}
ASEAN-China Free Trade Area (AC-FTA) is a free-trade cooperation between member countries of ASEAN with China on tariffs, import duties and taxes. Automatically, price of goods imported from China will be cheaper because there is no tariff as a cost for importers. In order to overcome the flood of imported products of China, the Indonesian government is trying to implement non-tariff barrier instrument, in this case, among others, SNI (Indonesian National Standard). Currently, there are many cases has discovered associated with low quality of Chinese products, especially for electronic products. After the agreement, based on the analysis of ASEAN-China FTA impact, China's frequent products purchased by indonesian customers are electronic (34\%), mobile phones (19\%), toys (11.1\%), non-electronic household appliances (9.9\%), clothing / textiles (9.3\%) and the remaining bags and shoes, transportation equipment, and computers and equipment. This is consistent with the view that one of the Chinese's can flood the domestic market, because the products are more competitive prices and cheaper than indonesia's products. For some products, SNI is enforced fairly effective, but for most electronic products SNI is still not effective, it is shown by the increases of imports after SNI policy. Due to the agreement of the ASEAN-China FTA, state revenue was reduced by 546146 thousand U.S\$, the largest lost was from the HS 841 451. For the national welfare, benefit of FTA is 98.445 (thousand U.S. \$). Based on the simulation results, the state Revenue and Welfare each are (-546 146) thousand U.S\$, and 98.445 thousand U.S\$, it can be concluded that the Cooperation Agreement with the ASEAN-China, Indonesia suffered an economic loss of 447.701 thousand U.S\$ ( revenue + welfare) from the EEE sector (Electric and Electronic Equipment).
\end{abstract}

Keywords: SNI, Electronic, ASEAN-China FTA

1. PENDAHULUAN

1.1. Latar Belakang
ASEAN-China Free Trade Area (AC-FTA) merupakan kerjasama perdagangan bebas antara negara negara anggota ASEAN dengan China mengenai penurunan tarif, bea masuk 
dan pajak. Kerjasama ini berlaku untuk semua negara ASEAN sesuai dengan kesepakatan yang telah di tandatangani dalam Framework Agreement on Comprehensive Economic Cooperation between the ASEAN and People's Republic of China yang ditandatangani oleh para Kepala Negara ASEAN dan China pada tanggal 4 November 2002 di Phnom Penh, Kamboja dan Agreement Trade in Goods dan Agreement Dispute Settlement Mechanism yang telah di tandatangani di Vientiane, Laos oleh para Menteri Ekonomi Negara ASEAN dan China pada tanggal 29 November 2004.

Tujuan utama Framework Agreement ACFTA adalah (a) memperkuat dan meningkatkan kerjasama perdagangan kedua pihak; (b) meliberalisasikan perdagangan barang dan jasa melalui pengurangan atau penghapusan tariff; (c) mencari area baru dan mengembangkan kerjasama ekonomi yang saling menguntungkan kedua pihak; (d) memfasilitasi integrasi ekonomi yang lebih efektif dengan negara anggota baru ASEAN dan menjembatani celah yang ada di kedua belah pihak.

Dalam kerjasama perdagangan bebas antara ASEAN dengan China diatur tentang kesepakatan penurunan tarif dan kerjasama dalam penghapusan tarif untuk mempermudah perdagangan internasional seperti yang ada pada WTO (World trade Organization). Konsekwensi dari adanya kesepakatan Negara Negara anggota ASEAN dengan China mengenai perdagangan bebas termasuk Indonesia akan berlaku mulai tahun 2010. ACFTA merupakan kesepakatan mengenai penurunan tarif impor sampai dengan nol persen bagi Negara Negara yang sudah menetapkan daftar barang barang yang bebas bea masuk dan pajak.

Secara otomatis harga barang yang diimpor dari China akan lebih murah karena tidak ada lagi tarif yang menjadi biaya bagi para importir. Barang barang tersebut masuk ke pasaran Indonesia dalam jumlah besar, sehingga dapat mempengaruhi tingkat harga dan kompetisi memperebutkan pasar domestik yang berakibat menekan industri dalam negeri apabila produk yang masuk tersebut lebih kompetitif (memiliki kualitas yang lebih baik dan harga yang lebih murah). Produk impor dari China dengan harga yang murah membanjiri Indonesia mengingat Indonesia dengan 230 juta penduduk, adalah pasar yang sangat besar bagi komoditas dan produk China. Banyak komoditas dan produk Indonesia yang sulit bersaing dengan produk impor dari China karena faktor harga. Ditambah dengan pola konsumsi masyarakat
Indonesia yang lebih mencari barang murah (kurang memperhatikan asal/nasionalisme dan komparasi kualitas), maka secara perlahan pasar produk lokal disaingi oleh produk China.

Dalam rangka menanggulangi banjirnya produk impor China, pemerintah Indonesia menerapkan instrument non-tariff barrier, dalam hal ini antara lain SNI (Standar Nasional Indonesia). Seiring dengan diterapkannya instrument non-tarif dalam hal ini standar, masih banyak ditemukan produk-produk yang memiliki kualitas rendah, terutama untuk produk elektronik. Rendahnya kualitas produk electronic and electric equipment dan China, terutama disebabkan antara lain mayoritas produk yang dihasilkan oleh China adalah mass products, dimana tidak melalui Quality Control yang ketat.

\subsection{Perumusan Masalah}

Untuk mencegah membanjirnya produk electronic and electric equipment China di pasar Indonesia, dan melindungi konsumen dan pasar domestik. Pemerintah Indonesia sampai dengan saat ini telah memberlakukan 19 SNI (Standar Nasional Indonesia) khusus untuk produk electronic and electric equipment sejak tahun 1990. Akan tetapi yang terjadi sampai saat ini, masih ditemukannya kasus-kasus yang terkait dengan kualitas produk China yang rendah.

Hal ini menimbulkan pertanyaan sejauh mana efektifitas dari penerapan Standar Nasional Indonesia (SNI) khususnya untuk produk electronic and electric equipment (EEE) Indonesia. Disamping itu, apa dampak dari penghapusan tarif produk electronic and electric equipment terhadap welfare dan government revenue.

\subsection{Tujuan Penelitian}

Tujuan penelitian adalah untuk mengetahui sejauh mana efektifitas dari penerapan SNI untuk produk electronic and electric equipment (EEE) Indonesia. Dan bagaimana dampak dari penghapusan tarif produk electronic and electric equipment terhadap welfare dan government revenue.

\section{DASAR TEORI}

\subsection{Kebijakan Standar Nasional Indonesia}

Untuk menjaga dan melindungi kepentingan domestik dari serbuan masuknya barang impor, kini banyak negara menggunakan instrumen non tarif, antara lain dengan pemberlakuan standar dan penilaian kesesuaian. Oleh karenanya, peran standar dan penilaian 
kesesuaian kini menjadi semakin besar dalam kegiatan perdagangan internasional. Hal ini ditandai dengan meningkatnya kegiatan standar dan penilaian kesesuaian di berbagai blok perdagangan regional maupun internasional, seperti ACCSQ (ASEAN Consultative Committee for Standards and Quality), APEC-SCSC (Standards and Conformance Sub-Committee), dan ASEM-TFAP-on SCA (Asian European Meeting-Trade Facilitation Action Plan on Standards and Conformity Assessment). Indonesia telah menandatangani kesepakatan pada beberapa organisasi dan blok perdagangan untuk melaksanakan liberalisasi perdagangan, antara lain WTO, AFTA, APEC, dan ASEM. Kesepakatan dalam blok-blok perdagangan yang diikuti memaksa Indonesia harus melaksanakan liberalisasi perdagangan internasional secara konsekwen. Berarti kebijakan perdagangan Indonesia yang selama ini masih mengandung unsur restriksi/proteksi harus secara berangsur-angsur dihilangkan. Keadaan ini juga mendorong meningkatnya peran standardisasi di Indonesia.

Peranan standardisasi dalam perekonomian nasional juga mengalami perkembangan yang berarti, misalnya diberlakukannya UU No. 8 tahun 1999 tentang Perlindungan Konsumen yang secara spesifik mengamanatkan bahwa pelaku usaha dilarang memproduksi dan/atau memperdagangkan barang/jasa yang tidak memenuhi standar yang dipersyaratkan; terbitnya PP 102 tahun 2000 tentang standardisasi nasional; meningkatnya peran aktif Indonesia dalam kegiatan standardisasi regional dan internasional seperti ISO (International Organization for Standardization), IEC (International Electrotechnical Commission), CAC (Codex Alimentarius Commission), ILAC (International Laboratory Accreditation Cooperation), APLAC (Asia Pasific Laboratory Accreditation Cooperation), dan sebagainya.

Ruang lingkup Sistem Standardisasi Nasional meliputi kelembagaan standardisasi, perumusan standar, penetapan standar, pemberlakuan standar, penerapan standar, akreditasi, sertifikasi, metrologi, pembinaan dan pengawasan standardisasi, kerja sama, informasi dan dokumentasi, pemasyarakatan, pendidikan dan pelatihan standardisasi serta penelitian dan pengembangan standardisasi

Namun di sisi lain, kesadaran masyarakat dan pelaku usaha terhadap standar dan mutu produk relatif masih rendah, jumlah standar nasional yang dapat mendukung produk industri masih dianggap belum mencukupi, peraturan yang mendorong terwujudnya penerapan standar yang efektif juga masih belum memadai, dan hal lain yang diperlukan dalam rangka memfasilitasi perdagangan dan terjaminnya mutu produk dalam negeri.

Mengingat pentingnya peran standardisasi di masa kini dan masa yang akan datang, maka diperlukan suatu sistem yang dapat dipakai sebagai landasan dalam menciptakan pola kebijakan dan program pengembangan standardisasi nasional di Indonesia.

SNI (Standar Nasional Indonesia) adalah standar yang dirumuskan dan ditetapkan melalui konsensus oleh unsur-unsur produsen, konsumen, regulator, dan para pakar. Untuk keperluan tertentu, pemerintah melalui keputusan menteri atau kepala lembaga pemerintah tertentu dapat memberlakukan SNI secara wajib sesuai dengan lingkup kewenangannya. Pemberlakuan suatu SNI secara wajib menjadikan ketentuan teknis yang ada dalam standar tersebut sebagai persyaratan yang harus dipenuhi oleh pelaku pasar. Oleh karena SNI dihasilkan melalui proses konsensus, maka diharapkan pemberlakuannya secara wajib juga dapat diterima oleh pelaku pasar. Walaupun demikian, pemberlakuan SNI wajib juga berpotensi menimbulkan hambatan transaksi perdagangan. Dengan demikian pemberlakuan SNI wajib harus dilaksanakan secara berhati-hati dengan memperhatikan kemampuan produsen, kepentingan konsumen, serta kesiapan sarana penunjang untuk menegakkan persyaratan pasar tersebut agar perkembangan persaingan pasar yang sehat dapat dijamin.

\subsection{Tinjauan Kebijakan ASEAN-China Free Trade Agreement}

ASEAN-China Free Trade Area (ACFTA) merupakan kesepakatan antara Negara-negara anggota ASEAN dengan China untuk mewujudkan kawasan perdagangan bebas dengan menghilangkan atau mengurangi hambatan-hambatan perdagangan barang baik tarif ataupun non tarif, peningkatan akses pasar jasa, peraturan dan ketentuan investasi, sekaligus peningkatan aspek kerjasama ekonomi untuk mendorong hubungan perekonomian para Pihak ACFTA dalam rangka meningkatkan kesejahteraan masyarakat ASEAN dan China.

Para kepala negara anggota ASEAN dan China pada tanggal 4 November 2004 di Phnom Penh, Kamboja telah menandatangani Framework Agreement on Comprehensive Economic Co-operation between The Association of Southeast Asian Nations and The People's Republic of China (ACFTA). Tujuan dari Framework Agreement AC-FTA tersebut adalah (a) memperkuat dan meningkatkan kerjasama ekonomi, perdagangan dan investasi kedua 
pihak; (b) meliberalisasikan perdagangan barang, jasa dan investasi, (c) mencari area baru dan mengembangkan kerjasama ekonomi yang saling menguntungkan kedua pihak; (d) memfasilitasi integrasi ekonomi yang lebih efektif dengan negara anggota baru ASEAN dan menjembatani gap yang ada di kedua belah pihak. Selain itu, kedua pihak juga menyepakati untuk memperkuat dan meningkatkan kerjasama ekonomi melalui (a) penghapusan tarif dan hambatan non tarif dalam perdagangan barang; (b) liberalisasi secara progresif perdagangan jasa; (c) membangun regim investasi yang kompetitif dan terbuka dalam kerangka ASEANChina FTA.

Dalam hal penurunan dan penghapusan tarif perdagangan barang, telah disepakati tiga skenario yaitu: (a) Early Harvest Programme (EHP); (b) Normal Track Programme; (c) Sensitive dan Highly Sensitive. The Early Harvest Programme (EHP), tujuannya adalah mempercepat implementasi penurunan tarif produk dimana program penurunan tarif bea masuk dilakukan secara bertahap dan efektif dimulai pada 1 Januari 2004 bagi produk EHP dan menjadi 0\% pada 1 Januari 2006. Pada Normal Track programme penurunan tarif bea masuk dimulai sejak tanggal 20 Juli 2005, yang menjadi $0 \%$ pada tahun 2010, dengan fleksibilitas pada produk-produk yang akan menjadi 0\% pada tahun 2012. Adapun produkproduk dalam kelompok Sensitive, akan dilakukan penurunan tarif mulai tahun 2012, dengan penjadwalan bahwa maksimun tarif bea masuk 20\% pada tahun 2012 dan akan menjadi 0-5\% mulai tahun 2018. Produk-produk Highly Sensitive akan dilakukan penurunan tarif bea masuknya 0-5\% pada tahun 2020.

Untuk mendapatkan preferensi penurunan tarif dengan menggunakan ketiga skenario tersebut disepakati Pengaturan Surat Keterangan Asal Barang (SKA) atau Rules of Origin (ROO) dengan ketentuan kandungan lokal ASEAN China FTA sebesar $40 \%$ yang secara operasional menggunakan SKA Form E. Penurunan dan penghapusan tarif bea masuk dalam Perdagangan Bebas ASEAN-China dilakukan melalui proses secara bertahap atas seluruh produk, hal ini dimaksudkan untuk tetap menjaga kepentingan perlindungan terhadap produk Indonesia yang dianggap belum mampu untuk bersaing dengan produk negara peserta FTA.

Jadi pada dasarnya, ASEAN-China Free Trade Area (ACFTA) merupakan kesepakatan antara Negara negara anggota ASEAN dengan China untuk mewujudkan kawasan perdagangan bebas dengan menghilangkan atau mengurangi hambatan-hambatan perdagangan barang baik tarif ataupun non tarif, peningkatan akses pasar jasa, peraturan dan ketentuan investasi, sekaligus peningkatan aspek kerjasama ekonomi untuk mendorong hubungan perekonomian para Pihak ACFTA dalam rangka meningkatkan kesejahteraan masyarakat ASEAN dan China.

Pada dasarnya, tujuan dari ASEAN-CHINA FTA adalah sebagai berikut :

a. Memperkuat dan meningkatkan kerjasama ekonomi, perdagangan, dan investasi antara negara-negara anggota.

b. Meliberalisasi secara progresif dan meningkatkan perdagangan barang dan jasa serta menciptakan suatu sistem yang transparan dan untuk mempermudah investasi.

c. Menggali bidang-bidang kerjasama yang baru dan mengembangkan kebijaksanaan yang tepat dalam rangka kerjasama ekonomi antara negaranegara anggota.

d. Memfasilitasi integrasi ekonomi yang lebih efektif dari para anggota ASEAN baru (Cambodia, Laos, Myanmar, dan Vietnam -CLMV) dan menjembatani kesenjangan pembangunan ekonomi diantara negara-negara anggota.

Berdasarkan hal-hal tersebut di atas, Indonesia pada dasarnya dapat memanfaatkan peluang dari adanya ASEAN-CHINA FTA antara lain :

a. Meningkatnya akses pasar ekspor ke China dengan tingkat tarif yang lebih rendah bagi produk-produk nasional.

b. Meningkatkanya kerjasama antara pelaku bisnis di kedua negara melalui pembentukan "Aliansi Strategis".

c. Meningkatnya akses pasar jasa di China bagi penyedia jasa nasional

d. Meningkatnya arus investasi asing asal China ke Indonesia

Terbukanya transfer teknologi antara pelaku bisnis di kedua negara.

\section{PEMBAHASAN}

\subsection{Profil Perdagangan Produk Elektronik dan} Elektrik

Sektor perdagangan di awal tahun 2010 dimulai dengan pemberlakuan ACFTA yang menimbulkan pro dan kontra dari masyarakat dan pelaku usaha. Sebagian pelaku usaha dan masyarakat menilai bahwa ACFTA sebagai tantangan bagi Indonesia untuk maju, namun 
sebagian lain menganggap ACFTA sebagai ancaman bagi industri dalam negeri.

Kalangan yang optimis menganggap bahwa dengan diberlakukannya ACFTA, maka hambatan tarif untuk produk ekspor dapat berkurang secara signifikan sehingga akan mendorong peningkatan produk ekspor dari Indonesia ke China. Sebaliknya, produk impor dari China juga memiliki peluang besar untuk mendominasi pasar Indonesia.

Kekhawatiran akan dominasi produk China di pasar Indonesia harus didasarkan pada data perdagangan antar indonesia dan beberapa negara. Berdasarka data BPS tahun 2010, nilai ekspor-impor total Indonesia ke beberapa negara masih menunjukkan surplus. Pada bulan Januari 2009, total ekpor nasional ke China mencapai US\$ 462,9 juta dan meningkat signifikan pada tahun 2010 menjadi US\$ 1011,7 juta. Nilai tersebut relatif lebih besar dibandingkan dengan ekspor Indonesia ke beberapa negara ASEAN lainnya sebesar US\$ 252,5 juta pada bulan Januari 2009 dan US\$ 367,2 juta pada Januari 2010, diluar Singapura, Malaysia, dan Thailand.

Sementara itu, total impor Indonesia dari China pada bulan Januari 2009 mencapai US\$ 1035,7 juta dan meningkat menjadi US\$ 1408 juta pada bulan Januari 2010. Secara relatif, nilai impor Indonesia dari beberapa negara ASEAN lebih kecil dibanding impor dari China. Pada bulan Januari 2009, total impor Indonesia dari negara anggota ASEAN hanya sebesar US\$ 51,2 juta dan meningkat tidak signifikan menjadi US\$102,6 juta pada bulan Januari 2010, diluar Singapura, Malaysia, dan Thailand

Tabel 1 Ekspor-Impor Indonesia ke China dan ASEAN

\begin{tabular}{|l|c|c|c|c|c|c|}
\hline \multirow{2}{*}{ Negara } & \multicolumn{3}{|c|}{ Ekspor Nasional } & \multicolumn{3}{c|}{ Impor Nasional } \\
\cline { 2 - 7 } & $\begin{array}{c}\text { Januari } \\
\mathbf{2 0 0 9}\end{array}$ & $\begin{array}{c}\text { Desember } \\
\mathbf{2 0 0 9}\end{array}$ & $\begin{array}{c}\text { Januari } \\
\mathbf{2 0 1 0}\end{array}$ & $\begin{array}{c}\text { Januari } \\
\mathbf{2 0 0 9}\end{array}$ & $\begin{array}{c}\text { Desember } \\
\mathbf{2 0 0 9}\end{array}$ & $\begin{array}{c}\text { Januari } \\
\mathbf{2 0 1 0}\end{array}$ \\
\hline China & 462,9 & 1206,8 & 1011,7 & 1035,7 & 1482,6 & 1408 \\
\hline Singapura & 580,7 & 713,8 & 701,5 & 651,5 & 784,9 & 784,2 \\
\hline Malaysia & 281,7 & 730,3 & 600,4 & 212,6 & 298,2 & 330,8 \\
\hline Thailand & 147,9 & 274,3 & 288,6 & 291,1 & 466,6 & 482,7 \\
\hline $\begin{array}{l}\text { ASEAN } \\
\text { lainnya }\end{array}$ & 252,5 & 436,2 & 367,2 & 51,7 & 136 & 102,6 \\
\hline Total & 7280,1 & 13348,1 & 11574,7 & 6600,6 & 10299,9 & 9543,3 \\
\hline
\end{tabular}

Sumber: BPS dalam www.setneg.go.id

Berdasarkan data tersebut, dapat dikatakan bahwa perdagangan Indonesia masih didominasi dengan China, dimana persentase nilai ekspor sebesar $8,74 \%$ dan impor sebesar $14,75 \%$ dari nilai total. Berdasarkan data yang diolah Litbang Kompas dalam edisi tanggal 3 Februari 2010 disebutkan bahwa produk China yang sering dibeli adalah elektronik (34\%), telepon seluler $(19 \%)$, mainan anak $(11,1 \%)$, alat rumah tangga non elektronik $(9,9 \%)$, pakaian/tekstil $(9,3 \%)$ dan selebihnya tas dan sepatu, alat transportasi, serta komputer dan perlengkapan. Pendapat ini sesuai dengan pandangan bahwa salah satu produk China yang dapat membanjiri pasar dalam negeri dan menggerus industri lokal adalah produk elektronik yang dinilai relatif berdaya saing dengan harga jual yang murah. Namun demikian, hal tersebut harus dilihat dari berbagai aspek antara lain dengan melihat perkembangan ekspor-impor produk elektronik Indonesia di pasar internasional. Sehingga, dapat diperoleh informasi umum apakah industri elektronik dalam negeri kehilangan potensi pasar atau tidak.

Perkembangan ekspor-impor Indonesia di pasar dunia dalam lima tahun terakhir menunjukkan pertumbuhan yang signifikan. Sejak tahun 2005, total ekspor non migas Indonesia mencapai US\$ 66.428,4 juta dan meningkat signifikan menjadi US\$ 92.012,3 juta pada tahun 2009 atau tumbuh 11,31\%. Namun, peningkatan total ekspor Indonesia tidak diikuti oleh pertumbuhan ekspor produk elektronik. Dengan menggolongkan HS HS 852580, $852190,844331,847330,852871,854430$, $847170,847160,852990$, dan 853690 dalam kategori produk elektronik, terlihat bahwa selama lima tahun terakhir terjadi penurunan yang signifikan dalam kinerja ekspor produk tersebut 


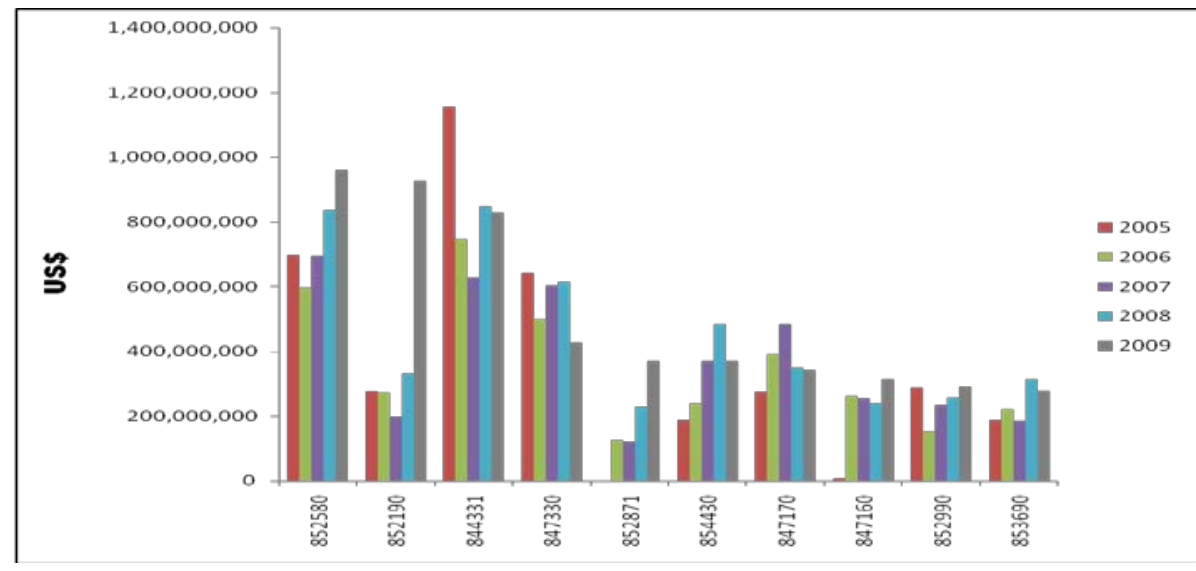

Gambar 1 Perkembangan Ekspor Produk Elektronik Indonesia

Dalam grafik terlihat bahwa rata-rata pertumbuhan ekspor produk elektronik berfluktuasi selama tahun 2005-2009. Beberapa produk mengalami pertumbuhan signifikan dalam lima tahun terakhir (HS 852580, 852190,
852871, 847160, dan 853690). Selebihnya adalah kategori produk elektronik yang mengalami penurunan.

Tabel 2 Perkembangan Ekspor Indonesia Menurut HS 6 Digit (Dalam US\$)

\begin{tabular}{|c|c|c|c|c|c|c|c|c|}
\hline HS & URAIAN & 2005 & 2006 & 2007 & 2008 & 2009 & $\begin{array}{c}\text { JAN-JAN } \\
2009\end{array}$ & $\begin{array}{c}\text { JAN-JAN } \\
2010\end{array}$ \\
\hline 852580 & $\begin{array}{l}\text { TELEVISION CAMERAS, DIGITAL } \\
\text { CAMERAS AND VIDEO CAMERA } \\
\text { RECORDERS. }\end{array}$ & $697,532,753$ & $595,739,543$ & $696,243,989$ & $835,683,092$ & $959,751,985$ & $27,565,931$ & $31,046,156$ \\
\hline 852190 & $\begin{array}{l}\text { VIDEO RECORDING OR REPRODUCING } \\
\text { APPARATUS, OTHER THAN MAGNETIC } \\
\text { TAPE-TYPE }\end{array}$ & $276,273,583$ & $270,138,127$ & $197,444,844$ & $331,230,449$ & $925,612,677$ & $46,796,054$ & $64,997,973$ \\
\hline 844331 & $\begin{array}{l}\text { MACHINES WHICH PERFORM TWO OR } \\
\text { MORE OF THE FUNCTIONS OF PRINTING, } \\
\text { COPYING OR FACSIMILE TRANSMISSION, } \\
\text { CAPABLE OF CONNECTING TO AN } \\
\text { AUTOMATIC DATA PROCESS }\end{array}$ & $1,155,694,865$ & $747,064,352$ & $626,618,188$ & $848,154,314$ & $828,305,171$ & $34,219,085$ & $61,399,803$ \\
\hline 847330 & $\begin{array}{l}\text { PARTS AND ACCESSORIES FOR } \\
\text { AUTOMATIC DATA PROCESSING } \\
\text { MACHINES AND UNITS THEREOF, } \\
\text { MAGNETIC OR OPTICAL READERS, } \\
\text { TRANSCRIBING MACHINES, ETC., NESOI }\end{array}$ & $641,605,105$ & $498,288,652$ & $604,177,561$ & $614,168,363$ & $425,369,836$ & $31,685,508$ & $36,247,851$ \\
\hline 852871 & $\begin{array}{l}\text { RECEPTION APPARATUS FOR } \\
\text { TELEVISION, NOT DESIGNED TO } \\
\text { INCORPORATE A VIDEO } \\
\text { DISPLAY/SCREEN }\end{array}$ & 15,411 & $126,668,643$ & $120,434,182$ & $228,442,037$ & $370,943,535$ & $40,075,961$ & $47,896,999$ \\
\hline 854430 & $\begin{array}{l}\text { INSULATED IGNITION WIRING SETS AND } \\
\text { OTHER WIRING SETS FOR VEHICLES, } \\
\text { AIRCRAFT AND SHIPS }\end{array}$ & $187,598,990$ & $238,946,761$ & $370,190,938$ & $484,463,851$ & $369,493,005$ & $14,298,646$ & $39,501,426$ \\
\hline 847170 & $\begin{array}{l}\text { STORAGE UNITS FOR DIGITAL } \\
\text { AUTOMATIC DATA-PROCESSING } \\
\text { MACHINES. }\end{array}$ & $274,400,563$ & $390,083,383$ & $484,855,249$ & $349,354,595$ & $340,666,842$ & $33,858,431$ & $16,329,509$ \\
\hline 847160 & $\begin{array}{l}\text { INPUT OR OUTPUT UNITS, FOR } \\
\text { PERSONAL AND MICRO COMPUTER }\end{array}$ & $6,126,776$ & $260,465,414$ & $253,221,810$ & $240,399,342$ & $312,557,548$ & $23,701,790$ & $24,552,219$ \\
\hline 852990 & $\begin{array}{l}\text { PARTS (EXCEPT ANTENNAS AND } \\
\text { REFLECTORS) FOR USE WITH RADIO } \\
\text { TRANSMISSION, RADAR, RADIO } \\
\text { NAVIGATIONAL AID, RECEPTION AND } \\
\text { TELEVISION APPARATUS, NESOI }\end{array}$ & $288,149,187$ & $153,176,917$ & $232,965,077$ & $256,064,743$ & $290,474,413$ & $21,810,373$ & $17,703,328$ \\
\hline 853690 & $\begin{array}{l}\text { ELECTRICAL APPARATUS FOR } \\
\text { SWITCHING, PROTECTING OR MAKING } \\
\text { CONNECTIONS TO OR IN ELECTRICAL } \\
\text { CIRCUITS, FOR A VOLTAGE NOT } \\
\text { EXCEEDING } 1,000 \text { V, NESOI }\end{array}$ & $187,427,524$ & $221,176,109$ & $184,957,155$ & $313,385,726$ & $278,358,907$ & $14,097,899$ & $27,581,125$ \\
\hline
\end{tabular}

Sumber: BPS diolah Kementerian Perdagangan 
Berdasarkan tabel, rata-rata pertumbuhan ekspor masih bernilai positif hingga bulan Januari 2010. Pertumbuhan terbesar dimiliki oleh produk dengan HS 852190 dengan rata-rata pertumbuhan mencapai US\$ 64,97 juta atau meningkat signifikan dibanding tahun sebelumnya yang hanya sebesar US\$ 46 juta

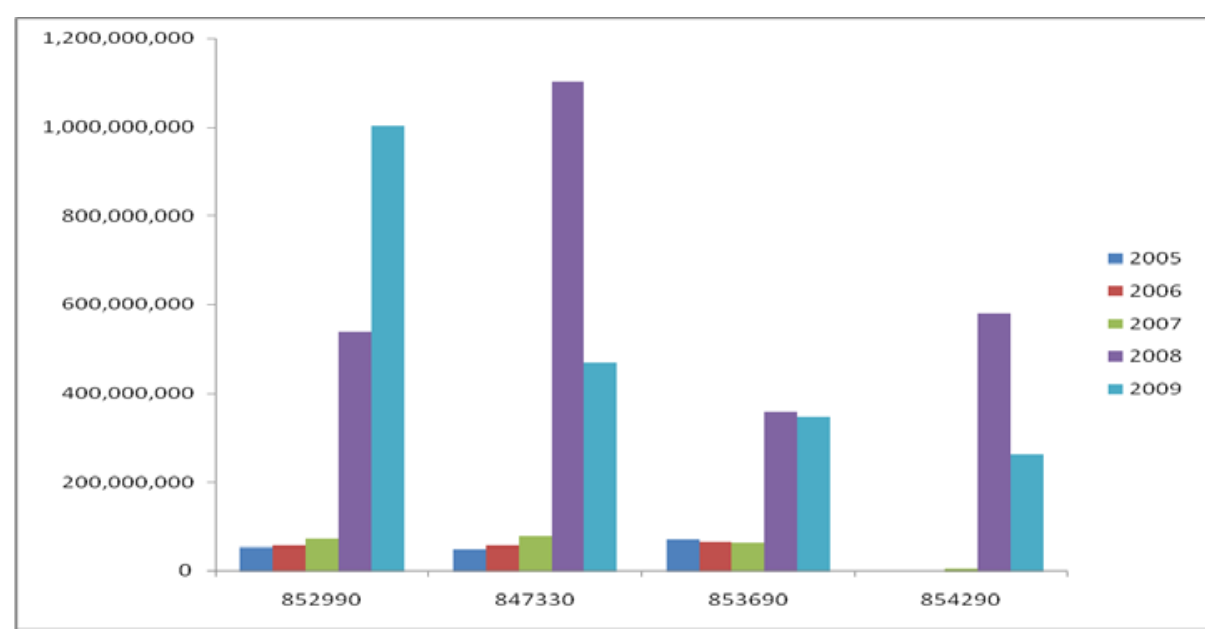

Gambar 2 Perkembangan Impor Produk Elektronik Indonesia

Sementara itu, impor produk elektronik dengan HS yang sama hanya dimiliki oleh produk dengan HS 852990, 847330, 853690, dan 854290. Dalam lima tahun terakhir, impor produk dengan HS 852990 menunjukkan kenaikan signifikan dimana pada tahun 2005, nilai impor produk tersebut hanya sebesar US\$ 53,47 juta kemudian mencapai US\$ 536,82 juta pada tahun 2008, dan secara signifikan meningkat menjadi US\$1.003 juta pada tahun 2009. Hanya produk dengan HS 847330 dan 854290 yang mengalami penurunan signifikan pada tahun 2009 masing-masing menjadi US\$ 469 juta dan US\$262 juta setelah pada tahun 2008 mencapai nilai tertinggi masing-masing sebesar US\$ 1.103 juta dan US\$ 581 juta

Tabel 3 Perkembangan Impor Indonesia Menurut HS 6 Digit (Dalam US\$)

\begin{tabular}{|c|l|c|c|c|c|c|c|c|}
\hline US & URAIAN & 2005 & 2006 & 2007 & 2008 & 2009 & $\begin{array}{c}\text { JAN-JAN } \\
2009\end{array}$ & $\begin{array}{c}\text { JAN-JAN } \\
2010\end{array}$ \\
\hline 852990 & $\begin{array}{l}\text { PARTS (EXCEPT ANTENNAS AND } \\
\text { REFLECTORS) FOR USE WITH RADIO } \\
\text { TRANSMISSION, RADAR, RADIO } \\
\text { NAVIGATIONAL AID, RECEPTION AND } \\
\text { TELEVISION APPARATUS, NESOI }\end{array}$ & $53,478,151$ & $55,776,610$ & $71,246,662$ & $536,819,197$ & $1,003,561,585$ & $30,670,638$ & $60,479,167$ \\
$\begin{array}{l}\text { PARTS AND ACCESSORIES FOR } \\
\text { AUTOMATIC DATA PROCESSING } \\
\text { MACHINES AND UNITS THEREOF, } \\
\text { MAGNETIC OR OPTICAL READERS, } \\
\text { TRANSCRIBING MACHINES, ETC., NESOI }\end{array}$ & $48,798,866$ & $56,183,832$ & $78,049,739$ & $1,103,480,247$ & $469,615,880$ & $27,820,471$ & $46,726,610$ \\
853690 & $\begin{array}{l}\text { ELECTRICAL APPARATUS FOR } \\
\text { SWITCHING, PROTECTING OR MAKING } \\
\text { CONNECTIONS TO OR IN ELECTRICAL } \\
\text { CIRCUITS, FOR A VOLTAGE NOT } \\
\text { EXCEEDING 1,000 V, NESOI }\end{array}$ & $71,026,666$ & $63,755,538$ & $61,792,841$ & $358,231,845$ & $346,146,690$ & $26,719,467$ & $38,148,005$ \\
854290 & $\begin{array}{l}\text { PARTS FOR ELECTRONIC INTEGRATED } \\
\text { CIRCUITS AND MICROASSEMBLIES }\end{array}$ & 410,255 & 110,913 & $3,617,640$ & $581,197,252$ & $262,604,677$ & $18,346,473$ & $13,822,979$ \\
\hline
\end{tabular}

Sumber: BPS diolah Kementerian Perdagangan

\subsection{Analisis Pra dan Post ASEAN-CHINA FTA} Berdasarkan data BPS, pada Januari 2009, total ekpor nasional Indonesia ke China mencapai US\$ 462,9 juta dan meningkat signifikan pada periode yang sama yaitu Januari tahun 2010 menjadi US\$1011,7 juta. Nilai tersebut relatif lebih besar dibandingkan dengan ekspor Indonesia ke beberapa negara ASEAN lainnya sebesar US\$252,5 juta pada bulan Januari 2009 dan US\$367,2 juta pada Januari 2010, diluar Singapura, Malaysia, dan Thailand. 
Sementara itu, total impor Indonesia dari China pada bulan Januari 2009 mencapai US\$ 1035,7 juta dan meningkat menjadi US\$ 1408 juta pada bulan Januari 2010. Secara relatif, nilai impor Indonesia dari beberapa negara ASEAN lebih kecil dibanding impor dari China. Pada bulan Januari 2009, total impor Indonesia dari negara anggota ASEAN hanya sebesar US\$ 51,2 juta dan meningkat tidak signifikan menjadi US\$102,6 juta pada bulan Januari 2010, diluar Singapura, Malaysia, dan Thailand. Membanjirnya produk impor asal china ditenggarai sebagai akibat adanya penurunan tarif dalam rangka Asean-China Free Trade Agreement.

Berdasarkan data yang diolah Litbang Kompas dalam edisi tanggal 3 Februari 2010 disebutkan bahwa produk China yang sering dibeli adalah elektronik (34\%), telepon seluler (19\%), mainan anak $(11,1 \%)$, alat rumah tangga non elektronik $(9,9 \%)$, pakaian/tekstil $(9,3 \%)$ dan selebihnya tas dan sepatu, alat transportasi, serta komputer dan perlengkapan. Pendapat ini sesuai dengan pandangan bahwa salah satu produk China yang dapat membanjiri pasar dalam negeri dan menggerus industri lokal adalah produk elektronik yang dinilai relatif berdaya saing dengan harga jual yang murah. Namun demikian, perlu diperhatikan apakah produk impor electronic dan electric equipment dari China memenuhi persyratan Standar Nasional Indonesia (SNI) yang telah diberlakukan secara wajib.

Standar merupakan salah satu instrumen non tarif yang sering diterapkan. Standar Nasional Indonesia (SNI) yang telah diberlakukan secara wajib dan yang telah dinotifikasi di WTO telah mencapai 47 standar, namun yang terkait dengan produk elektronik dan electric equipment baru mencapai 7 standard yaitu lampu swa-ballast, saklar, tusuk kontak dan kotak kontak, MCB, kipas angin, baterai primer - bagian 1: umum dan baterai primer - bagian 2 : spesifikasi fisik dan listrik. Dari hasil konversi SNI ke Harmonized System (HS), diperoleh hasil sebagai berikut

\footnotetext{
a. SNI 04-6504-2001 - Lampu Swa-Ballast HS8539.31.90.90
}

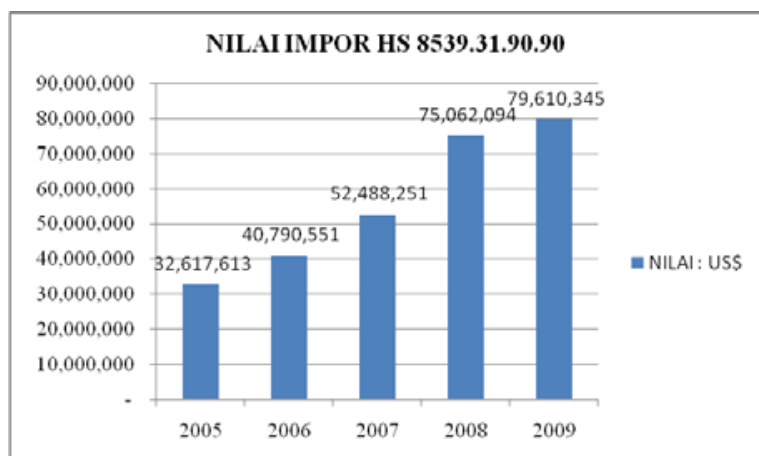

Gambar 3 Nilai Ekspor HS 8539.31.90.90

(Sumber: Data BPS, diolah)

Dari data BPS, menunjukkan bahwa untuk impor HS 8539.31.90.90, sejak tahun 2005 hingga tahun 2009 mengalami kenaikan yang cukup signifikan yaitu dari US\$ 32,617,613 pada tahun 2005 menjadi US\$79,610,345 pada tahun 2009. Kenaikan impor ini salah satunya adalah adanya penurunan tarif bea masuk karena AC-FTA menjadi 5\% pada 2007 dan menjadi $0 \%$ pada tahun 2009, sedangkan tarif bea masuk yang berlaku secara MFN sebesar $15 \%$.

Instrumen non tarif yang senantiasa digunakan untuk membendung impor adalah instrumen standar. Untuk HS ini Indonesia telah menerapkan standar wajib yang diterapkan baik untuk produk produksi dalam negeri maupun produk impor. Namun, kenaikan impor setiap tahun menunjukkan bahwa penerapan standar yang telah dilakukan belum cukup efektif membendung impor. Hal ini bisa disebabkan beberapa hal, yaitu diantaranya acuan standar yang diterapkan sudah tidak sesuai dengan acuan revisi terbaru, sedangkan barang impor yang masuk telah menerapkan standar dengan acuan revisi terbaru. Pengawasan akan penerapan SNI belum cukup efektif dilakukan disebabkan oleh beberapa hal diantaranya yang utama adalah, terbatasnya sumber daya manusia pengawas barang beredar.

b. SNI 04-6203.1-2006 - Saklar - HS
8536.50 .69 .00 


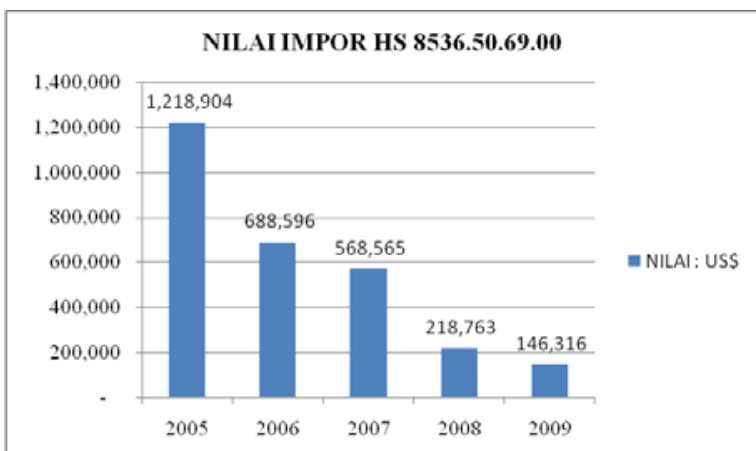

Gambar 4 Nilai Ekspor HS 8536.50.69.00

(Sumber: Data BPS, diolah)

Dari grafik diatas, terlihat bahwa sejak tahun 2005, untuk HS 8536.50.39.00 mengalami penurunan yang signifikan, dari sebesar US\$ 1.218.904 pada tahun 2005 turun menjadi US\$ 146.316 pada tahun 2009. Penurunan impor ini menunjukkan bahwa, walaupun tarif bea masuk dalam kerangka AC-FTA turun menjadi $5 \%$ pada tahun 2009, namun terdapat hambatan Non Tarif yang mengakibatkan Impor HS tersebut turun secara signifikan. Hal tersebut menunjukkan cukup efektifnya penerapan hambatan non tarif yaitu SNI yang telah mengacu pada revisi internasional terbaru sejak tahun 2006.

c. SNI 04-3892.1-2006 - Tusuk Kontak dan Kotak Kontak - HS 8536.69.11.00

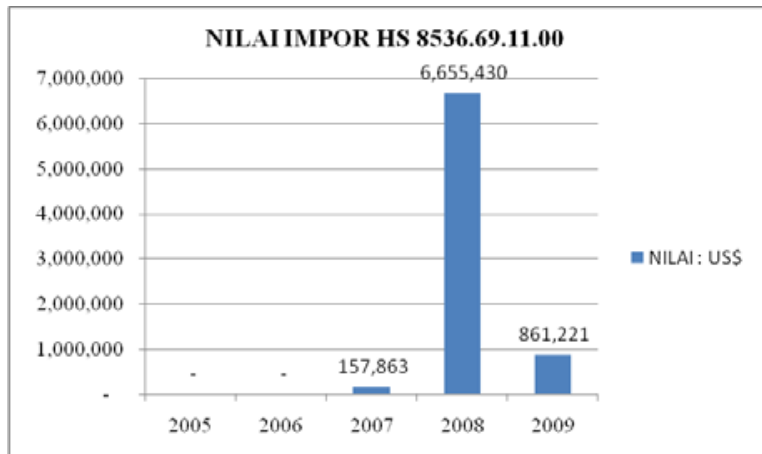

Gambar 5 Nilai Ekspor HS 8536.69.11.00 (Sumber: Data BPS, diolah)

Untuk HS 8536.69.11.00, pada tahun 2005 dan 2006, Indonesia tidak mengimpor dari China, pada tahun 2007 mulai ada impor sebesar US\$ 157.863 dan mengalami lonjakan yang sangat drastis pada tahun 2008 menjadi sebesar US\$ 6.655.430 dan pada tahun 2009 mengalami penurunan sehingga menjadi US\$ 861.221. Kenaikan impor dari tahun 2007 ke tahun 2008 kemungkinan besar terjadi karena tarif bea masuk pada saat itu sebesar 8\%. Namun penurunan yang terjadi pada tahun 2009 yang sangat drastis menunjukkan efektifnya instrumen non tarif yang menjadi penyebab penurunan impor, walaupun tarif bea masuk dalam rangka AC FTA pada saat itu sudah diturunkan menjadi sebesar $5 \%$. Efektifitas penerapan SNI pada produk ini terlihat pada tahun 2009, walaupun SNI wajib telah diterapkan pada tahun 2006.

\section{d. SNI 04-6507.1-2006 - MCB - HS 8536.20 .90 .00}

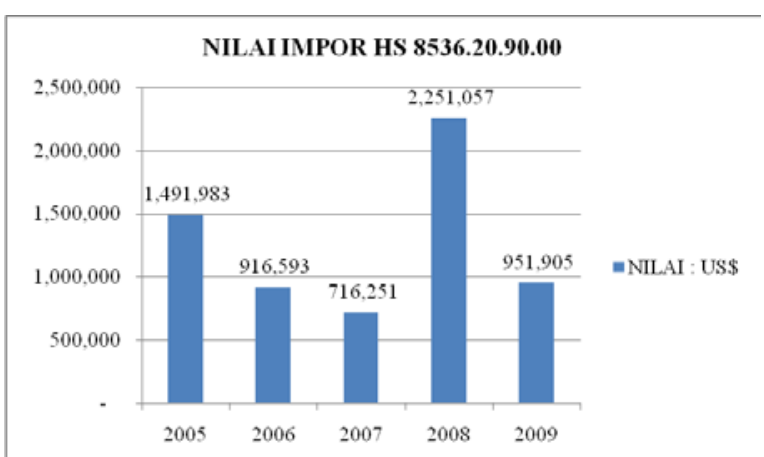

Gambar 6 Nilai Ekspor HS 8536.20.90.00 (Sumber: Data BPS, diolah)

Pada grafik diatas, terlihat bahwa untuk HS 8536.20.90.00 terjadi fluktuasi impor dari China yaitu sebesar US\$1.491.983 pada tahun 2005 dan terjadi penurunan pada tahun 2007 menjadi sebesar US\$ 716.251, namun mengalami lonjakan impor yang sangat besar, sehingga pada tahun 2008 impor dari China untuk HS ini menjadi sebesar US\$ 2.251.057 dan kembali mengalami penurunan pada tahun 2009 menjadi sebesar US\$ 951.905. Besaran bea masuk untuk HS ini pada tahun 2007 adalah $5 \%$ dan menjadi $0 \%$ pada tahun 2009. Menurunnya impor dari China pada tahun 2009 menunjukkan bahwa penurunan bea masuk tidak menyebabkan impor dari China meningkat. Penerapan SNI wajib untuk produk ini tidak terlalu efektif, terlihat walau diterapkan sejak tahun 2006, namun hanya cukup menekan impor pada tahun 2007. Pada tahun 2008 impor melonjak cukup drastis, kemungkinan hal ini disebabkan produk China menggunakan standar dengan acuan revisi internasional yang lebih baru dibandingkan dengan standar yang diadopsi oleh Indonesia. Namun penurunan kembali impor pada tahun 2009, kemungkinan disebabkan adanya pergeseran pasar negara peng ekspor produk tersebut, dari China ke negara peng ekspor lainnya.

e. SNI 04-6292.2.80-2006 - Kipas Angin - HS 8414.51.10.00 


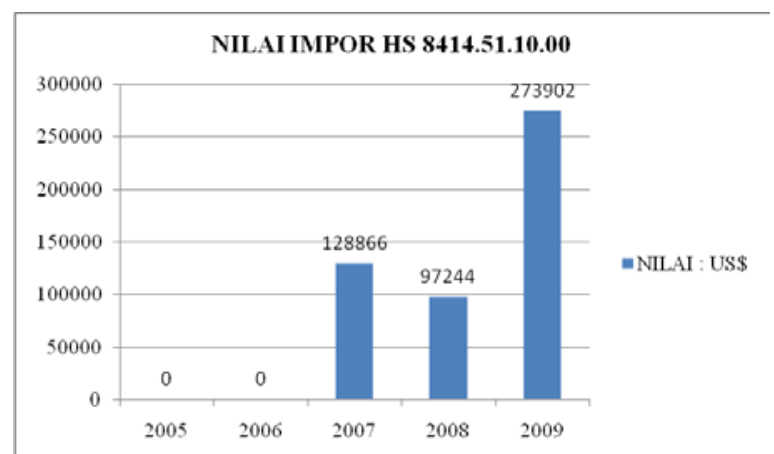

Gambar 7 Nilai Ekspor HS 8414.51.10.00 (Sumber: Data BPS, diolah)

Untuk HS 8414.51.10.00, pada tahun 2005 dan 2006 Indonesia tidak mengimpor dari China, namun pada tahun 2007 terjadi impor sebesar US\$ 128.866 dan terjadi penurunan pada tahun 2008 namun meningkat kembali pada tahun 2009 sebesar US\$273.902. Peningkatan impor ini kemungkinan terjadi karena turunnya bea masuk dari 8\% pada tahun 2008 menjadi $5 \%$ pada tahun 2009. Untuk produk ini, penerapan standard dirasa kurang efektif karena impor kembali meningkat cukup pesat pada tahun

2009. Kemungkinan yang terjadi adalah standard yang diacu China mengadopsi standard internasional revisi terbaru.

f. SNI 04-2051.1-2004 - Baterai Primer Bagian 1 : Umum - HS 8506.10.10.00

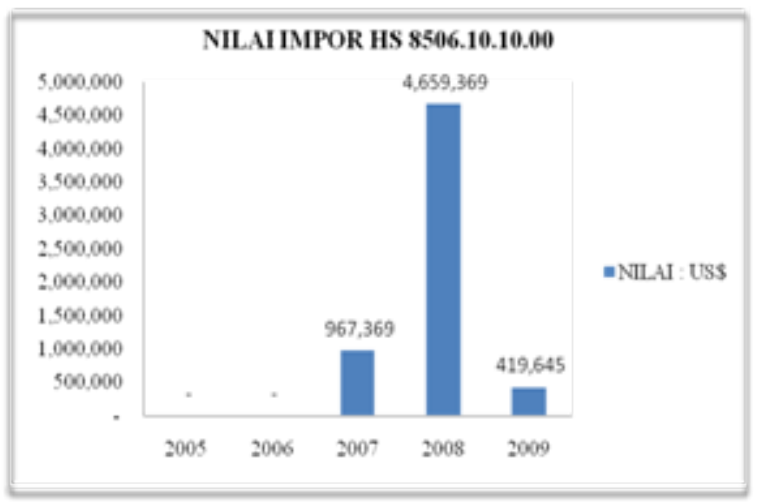

Gambar 8 Nilai Ekspor HS 8506.10.10.00 (Sumber: Data BPS, diolah)

Dari grafik diatas, terlihat bahwa impor HS ini pada periode tahun 2007 hingga 2008 mengalami peningkatan signifikan. Kendati pada tahun 2009 tarif bea masuk telah diturunkan menjadi 5\% dari $8 \%$ pada tahun sebelumnya, pada tahun 2009 impor menurun sangat drastis sehingga menjadi US\$ 419.645. Penerapan SNI wajib untuk produk ini cukup efektif, terlihat dari turunnya impor pada tahun 2007. Akan tetapi pada tahun 2008 impor melonjak cukup drastis, kemungkinan hal ini disebabkan produk China menggunakan standard dengan acuan revisi internasional yang lebih baru dibandingkan dengan standard yang diadopsi oleh Indonesia. Namun, penurunan impor pada tahun 2009 kemungkinan disebabkan adanya pergeseran pasar negara peng impor produk tersebut dari China ke negara lainnya.

g. SNI 04-2051.2-2004 - Baterai Primer Bagian 2 : Spesifikasi Fisik dan Listrik HS 8506.10.90.00

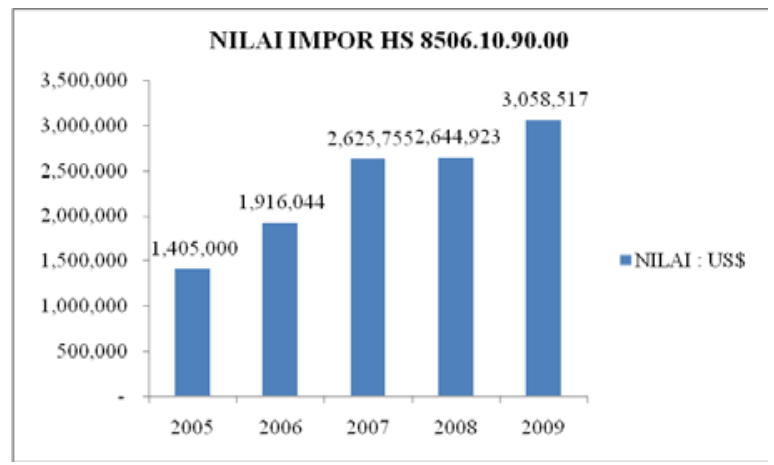

Gambar 9 Nilai Ekspor HS 8506.10.90.00 (Sumber: Data BPS, diolah)

Untuk HS 8506.10.90.00, impor dari China senantiasa meningkat dari sebesar US\$ 1.405.000 pada tahun 2005 menjadi US\$ 3.058.517 pada tahun 2009. Peningkatan impor ini selain diakibatkan adanya penurunan tarif yaitu menjadi $5 \%$ pada tahun 2009, juga disebabkan karena kurang efektifnya penerapan SNI wajib. Kurang efektif ini dikarenakan acuan standard yang diadopsi oleh Indonesia masih menggunakan acuan internasional yang lama.

\section{h. HS 8506.50.00.00}

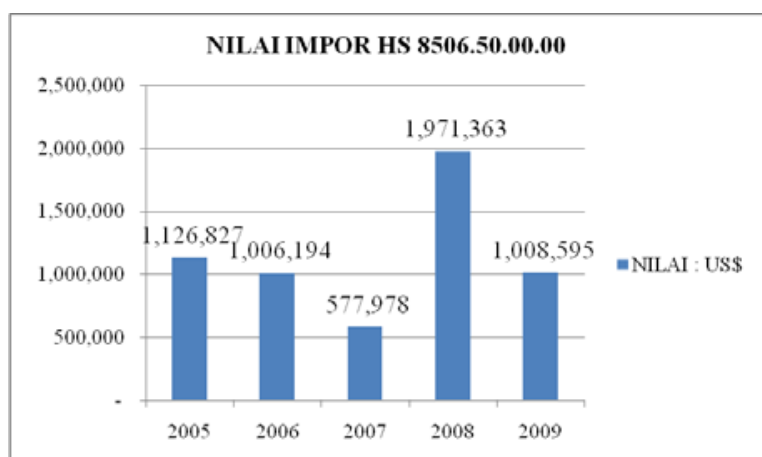

Gambar 10 Nilai Ekspor HS 8506.50.00.00 (Sumber: Data BPS, diolah) 
Impor Indonesia dari China untuk HS ini mengalami penurunan dari tahun 2005 hingga tahun 2007 namun mengalami kenaikan pada tahun 2008 walau akhirnya menurun kembali pada tahun 2009. Disini terlihat penerapan SNI cukup efektif menurunkan Impor hingga tahun 2007, kemudian SNI menjadi kurang efektif pada tahun 2008, hal ini kemungkinan disebabkan China memperbaharui standard internasionalnya untuk HS ini. Kemudian pada tahun 2009 impor kembali turun, hal ini kemungkinan disebabkan terjadi pergeseran pasar negara pengimpor produk tersebut dari China ke negara pengimpor lainnya.

\section{i. HS 8506.80.10.00}

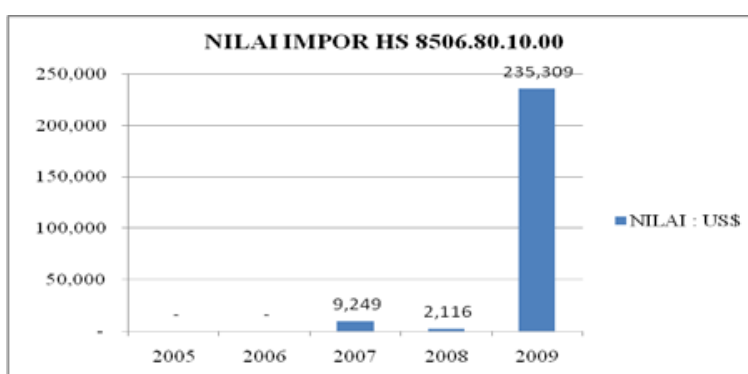

Gambar 11 Nilai Ekspor HS 8506.80.10.00 (Sumber: Data BPS, diolah)

Impor Indonesia HS 8506.80.10.00 dari China pada tahun 2007 mencapai sebesar US\$ 9.249, akan tetapi mengalami penurunan pada tahun 2008. Pada tahun 2009, terjadi Ionjakan yang sangat drastis yaitu sebesar US\$ 235.309 dibandingkan tahun 2008 sebesar US\$2.116. kenaikan ini disebabkan salah satunya oleh penurunan tarif menjadi $5 \%$ pada tahun 2009, padahal pada tahun ini Penurunan tarif dibarengi oleh penerapan instrumen non tarif diharapkan dapat menghambat impor. Disini terlihat bahwa penerapan standard sebagai salah satu instrumen non tarif kurang efektif dilaksanakan, terlihat dari melonjaknya nilai impor HS tersebut pada tahun 2009.

Secara keseluruhan, instrumen standar yang digunakan Indonesia dalam membendung impor khususnya impor dari China sebagai akibat adanya Asean-China FTA belum efektif. Hal ini terlihat dari masih banyaknya impor Indonesia dari China untuk produk-produk electronic dan electric equipment, masih sedikitnya standar wajib yang di terapkankan untuk produk electronic dan electric equipment dan standar yang digunakan masih mengacu pada standar internasional yang lama. Berdasarkan data survey lapangan, Standar yang saat ini banyak digunakan oleh perusahaan elektronik dan peralatan elektrik (electric equipment) di Surabaya adalah Standar Nasional Indonesia dan beberapa standar yang ditetapkan oleh importir diantaranya yaitu Philipines Standard, Thai Standard, IRAM-safety (Argentina), KTL-safety (Korea) serta IEC-safety and performance for scandescut lamps \& fluorescence lamps.

Untuk saat ini, rata-rata perusahaan elektronik dan peralatan elektrik (electric equipment) yang ada diSurabaya belum memiliki laboratorium uji sendiri, sehingga mereka harus mengujikan produk mereka ke Lembaga Sertfikasi Mutu (LSM) baik yang ada di Surabaya (BARISTAN) maupun di Jakarta (SUCOFINDO, PLN, LIPI dan lab uji yang dimiliki Panasonic), bahkan ada perusahaan dengan modal asing yang seringkali juga diuji oleh negara importirnya. Sementara itu laboratorium uji yang ada di Surabaya maupun Jawa Timur secara umum hanya satu yaitu Balai Riset dan Standardisasi Industri Surabaya (BARISTAN), namun Baristan ini juga belum terakreditasi (untuk peralatan listrik sedang dalam proses assesstment dan untuk produk elektronik sedang dalam persiapan akreditasi). Disamping itu Baristan juga terkendala dengan kekurangan sumber daya manusia, kesulitan akan zat yang digunakan sebagai acuan (harganya sangat mahal).

Selama ini perusahaan merasa bahwa laboratorium uji tempat mereka mengujikan produk masih belum mampu menguji semua parameter yang disyaratkan dan biaya yang dibebankan mahal dan juga masih terbebani dengan transportation cost (untuk pengujian di Jakarta). Sementara itu di negara importir khusunya untuk impor ke Philipina dan Thailand, produk-produk tersebut masih diuji kembali. Penggalakan pembangunan laboratorium uji di daerah-daerah yang mampu menguji semua parameter uji yang selama ini disyaratkan harus segera dilakukan. Disamping itu waktu dan biaya proses akreditasi laboratorium uji diharapkan tidak memakan waktu lama dan biaya yang mahal. Untuk penerapan dan pembuatan SNI selama ini dianggap terlalu lama oleh para pengusaha karena tidak langsung 'adopt' dari standar internasional

Dari data sekunder maupun hasil survey menunjukkan bahwa revisi terhadap standar wajib yang diterapkan Indonesia harus segera dilakukan khususnya untuk produk electronic dan electronic equipment mengingat dengan adanya Asean China FTA dimana tarif bea masuk menjadi relatif kecil bahkan $0 \%$, memungkinkan Indonesia menjadi pasar ekspor negara mitra kerjasama Indonesia. 
Revisi terhadap standar wajib dapat dilakukan dengan cara mengadopsi standard internasional revisi terbaru dengan tetap memperhatikan kemampuan industry sejenis didalam negeri.

\subsection{Analisis Dampak ASEAN-CHINA FTA terhadap Penerimaan Negara dan Kesejahteraan}

Analisa pengaruh perjanjian kerjasama ASEANChina bagi Indonesia ini menggunakan model The World Integrated Trade Solution (WITS). WITS merupakan model yang mengintegrasikan beberapa database mulai dari data perdagangan bilateral, aliran barang, maupun tipe dan tingkat proteksi perdagangan. Model WITS dilengkapi dengan model simulasi SMART yang dapat menghitung dampak penurunan tarif secara multilateral, penurunan tarif dalam kerangka "preferential agreement" (FTA atau EHP), maupun penurunan tarif secara unilateral.
SMART merupakan model "multi-country and multi commodity partial equilibrium".

Keunggulan Smart sebagai sebuah model partial equilibrium adalah dapat menampilkan hasil simulasi 1) trade creation, 2) trade diversion, 3) revenue impact, 4) market view 5) welfare effect dan 6) exporter view. Adapun sumber data perdagangan yang digunakan Smart berasal dari COMTRADE, sedangkan sumber data tarif berasal dari TRAINS. Adapun data yang digunakan dalam seluruh simulasi ini berdasarkan pada data Comtrade tahun 2004.

\section{a. Pengaruh terhadap Penerimaan Negara}

Dalam kajian ini pengaruh yang dilihat akibat penerapan pengaruh perjanjian kerjasama ASEAN-China bagi Indonesia adalah, pengaruhnya terhadap penerimaan negara (revenue impact) dan kesejahteraan nasional (welfare impact)..

Tabel 4 Perubahan Penerimaan Negara Akibat Perjanjian Kerjasama ASEAN-China Bagi Indonesia

\begin{tabular}{|c|c|c|}
\hline Product & HSCode & RevenueEffect \\
\hline HS. & 841451 & -546.146 \\
\hline HS. & 850610 & -198.841 \\
\hline HS. & 850650 & -1.368 \\
\hline HS. & 850680 & -0.009 \\
\hline HS. & 853620 & 0.000 \\
\hline HS. & 853650 & $-99,743$ \\
\hline HS. & 853669 & 0.000 \\
\hline HS. & 853931 & -0.000 \\
\hline & Total & -846.108 \\
\hline
\end{tabular}

Sumber : Comtrade, diolah

Tabel 4. di atas menunjukkan perubahan negatif penerimaan pemerintah dari impor sektor industri elektronik, akibat pelaksanaan perjanjian ASEAN-China FTA. Tabel 4. memperlihatkan bahwa penerimaan negara berkurang sebesar (546.146) ribu US\$, penerimaan negara terbesar yang hilang adalah dari HS 841451 akibat adanya perjanjian ASEAN-China FTA.

Akan tetapi, walaupun penerimaan negara berkurang, secara ekonomi harus dilihat juga dampaknya terhadap kesejahteraan secara keseluruhan seperti yang tersaji pada Tabel 5 berikut.

Tabel 5 Perubahan Kesejahteraan Negara Akibat Perjanjian Kerjasama ASEAN-China bagi Indonesia

\begin{tabular}{|c|c|c|c|}
\hline Product & HS Code & $\begin{array}{c}\text { TradeTotalEffect } \\
\mathbf{( \$ \mathbf { 0 0 0 } )}\end{array}$ & $\begin{array}{c}\text { Welfare } \\
\mathbf{( \$ \mathbf { 0 0 0 } )}\end{array}$ \\
\hline HS. & 841451 & $4.135,619$ & 161,220 \\
\hline HS. & 850610 & 176,627 & 2,032 \\
\hline HS. & 850650 & 0,835 & 0,010 \\
\hline
\end{tabular}




\begin{tabular}{|c|c|c|c|}
\hline HS. & 850680 & 0,005 & 0,000 \\
\hline HS. & 853620 & 0,000 & 0,000 \\
\hline HS. & 853650 & 84,657 & 1,793 \\
\hline HS. & 853669 & 0,000 & 0,000 \\
\hline HS. & 853931 & 0,000 & 0,000 \\
\hline \multicolumn{2}{|r|}{ Total } & $4.397,743$ & 165,054 \\
\hline
\end{tabular}

Sumber : Comtrade, diolah

\section{b. Pengaruh terhadap Kesejahteraan}

Hasil simulasi penurunan tarif Indonesia terhadap produk impor elektronik dari China juga menunjukkan perubahan dalam kesejahteraan konsumen (surplus konsumen). Surplus konsumen menunjukkan nilai positif, berdasarkan hal tersebut dapat disimpulkan bahwa, dengan adanya penerapan perjanjian ASEAN-China FTA, Indonesia mendapatkan keuntungan kesejahteraan nasional sebesar 98,445 (ribu US\$).

Berdasarkan hasil simulasi diatas, baik terhadap penerimaan negara maupun kesejahteraan dengan besaran masing-masing (546.146) ribu US\$, dan 98.445 ribu US\$, dapat disimpulkan bahwa dengan adanya Perjanjian Kerjasama ASEAN-China, Indonesia mengalami kerugian ekonomi sebesar 447.701 ribu US\$ (revenue + welfare) dari sektor EEE (Electric and Electronic Equipment).

\section{KESIMPULAN DAN SARAN}

\subsection{Kesimpulan}

1. Setelah adanya kesepakatan ASEAN-China FTA, produk China yang sering dibeli adalah elektronik (34\%), telepon seluler (19\%), mainan anak $(11,1 \%)$, alat rumah tangga non elektronik $(9,9 \%)$, pakaian/tekstil $(9,3 \%)$ dan selebihnya tas dan sepatu, alat transportasi, serta komputer dan perlengkapan. Hal ini sesuai dengan pandangan bahwa salah satu produk China yang dapat membanjiri pasar dalam negeri dan menggerus industri lokal adalah produk elektronik yang dinilai relatif berdaya saing dengan harga jual yang murah.

2. Standar Nasional Indonesia (SNI) yang telah diberlakukan secara wajib dan yang telah dinotifikasi di WTO telah mencapai 47 standard, untuk yang terkait dengan produk electronic dan electric equipment baru mencapai 7 standard yaitu lampu swaballast, saklar, tusuk kontak dan kotak kontak, MCB, kipas angin, baterai primer bagian 1 : umum dan baterai primer - bagian 2 : spesifikasi fisik dan listrik.
3. Kenaikan impor HS HS 8539.31.90.90 setiap tahun menunjukkan bahwa penerapan standard yang telah dilakukan belum cukup efektif membendung impor. Hal ini bisa disebabkan beberapa hal, yaitu diantaranya acuan standard (SNI wajib) yang diterapkan sudah tidak sesuai dengan acuan revisi terbaru, sedangkan barang impor yang masuk telah menerapkan standard dengan acuan revisi terbaru.

4. Impor HS 8536.50.39.00 mengalami penurunan yang signifikan, walaupun tarif bea masuk dalam kerangka AC-FTA turun menjadi $5 \%$ pada tahun 2009. Hal tersebut menunjukkan cukup efektifnya penerapan hambatan non tarif yaitu SNI wajib yang telah mengacu pada revisi internasional terbaru sejak tahun 2006.

5. Penurunan impor HS 8536.69.11.00 yang terjadi pada tahun 2009 yang sangat drastis menunjukkan efektifnya instrumen non tarif (SNI wajib) yang menjadi penyebab penurunan impor, walaupun tarif bea masuk dalam rangka AC FTA pada saat itu sudah diturunkan menjadi sebesar $5 \%$.

6. Menurunnya impor untuk HS 8536.20.90.00 dari China pada tahun 2009 menunjukkan bahwa penurunan bea masuk tidak menyebabkan impor dari China meningkat. Penerapan SNI wajib untuk produk ini tidak terlalu efektif, terlihat walau diterapkan sejak tahun 2006, namun hanya cukup menekan impor pada tahun 2007.

7. Untuk produk HS 8414.51.10.00, penerapan SNI wajib dirasa kurang efektif karena impor kembali meningkat cukup pesat pada tahun 2009 setelah sebelumnya turun pada tahun 2008.

8. Penerapan SNI wajib untuk HS 8506.80.10.00 cukup efektif, terlihat dari turunnya impor pada tahun 2007. Akan tetapi pada tahun 2008 impor melonjak cukup drastis, kemungkinan hal ini disebabkan produk China menggunakan standard dengan acuan revisi internasional yang lebih baru dibandingkan dengan standard yang diadopsi oleh Indonesia. Namun, penurunan impor pada tahun 2009 
kemungkinan disebabkan adanya pergeseran pasar negara peng impor produk tersebut dari China ke negara lainnya.

9. Untuk HS 8506.10.90.00, impor dari China senantiasa meningkat dari sebesar US\$ 1.405.000 pada tahun 2005 menjadi US\$ 3.058.517 pada tahun 2009. Peningkatan impor HS 8506.10.90.00 selain diakibatkan adanya penurunan tarif yaitu menjadi $5 \%$ pada tahun 2009, juga disebabkan karena kurang efektifnya penerapan SNI wajib. Kurang efektif ini dikarenakan acuan standard yang diadopsi oleh Indonesia masih menggunakan acuan internasional yang lama.

10. Impor Indonesia dari China untuk HS ini mengalami penurunan dari tahun 2005 hingga tahun 2007 namun mengalami kenaikan pada tahun 2008 walau akhirnya menurun kembali pada tahun 2009. Disini terlihat penerapan SNI cukup efektif menurunkan Impor hingga tahun 2007, kemudian SNI menjadi kurang efektif pada tahun 2008, hal ini kemungkinan disebabkan China memperbaharui standard internasionalnya untuk HS ini. Kemudian pada tahun 2009 impor kembali turun, hal ini kemungkinan disebabkan terjadi pergeseran pasar negara pengimpor produk tersebut dari China ke negara pengimpor lainnya.

11. Kenaikan impor HS 8506.80.10.00 ini disebabkan salah satunya oleh penurunan tarif menjadi $5 \%$ pada tahun 2009, padahal pada tahun ini Penurunan tarif dibarengi oleh penerapan instrumen non tariff (SNI wajib). Disini terlihat bahwa penerapan standard sebagai salah satu instrumen non tarif kurang efektif dilaksanakan, terlihat dari melonjaknya nilai impor HS tersebut pada tahun 2009.

12. Akibat adanya perjanjian ASEAN-China FTA, penerimaan negara berkurang sebesar 546.146 ribu US\$, penerimaan negara terbesar yang hilang adalah dari HS 841451 . Dengan adanya penerapan perjanjian ASEAN-China FTA, Indonesia mendapatkan keuntungan kesejahteraan nasional sebesar 98,445 (ribu US\$).

13. Berdasarkan hasil simulasi, baik terhadap Penerimaan negara maupun Kesejahteraan dengan besaran masing-masing $(-546.146)$ ribu US\$, dan 98.445 ribu US\$, dapat disimpulkan bahwa dengan adanya Perjanjian Kerjasama ASEAN-China, Indonesia mengalami kerugian ekonomi sebesar 447.701 ribu US\$ (revenue + welfare) dari sektor EEE (Electric and Electronic Equipment).

\subsection{Saran}

1. Memperluas cakupan produk EEE (Electric and Electronic Equipment) yang harus memiliki Standard Nasional Indonesia (SNI) Wajib, hal ini bisa dilakukan dengan mengadopsi langsung dari Standard Internasional revisi terbaru yang telah ada

2. Merevisi SNI produk EEE (Electric and Electronic Equipment) yang sudah ada dengan acuan Standard Internasional revisi terbaru

3. Mengefektifkan fungsi pengawasan barang beredar di pasar domestik oleh Kementerian Perdagangan, khususnya Direktorat Pengawasan barang beredar.

4. Memperbaiki sistem ketenagakerjaan, logistik dan infrastruktur industri, serta menghilangkan ekonomi biaya tinggi yang dapat mengurangi daya saing produk EEE (Electric and Electronic Equipment) nasional.

\section{DAFTAR PUSTAKA}

Departemen Perdagangan. (2006). Buletin Mutu Dit. PPMB No 5 Nop 2006.

BPPT. (2007). Harmonisasi Standar Untuk Peningkatan Daya Saing Kawasan Asia Tenggara.

Departemen Perindustrian. (2007). Katalog Standar Nasional Indonesia Bidang Industri berdasarkan Panitia teknis, Pusat Standarisasi-Badan Penelitian dan Pengembangan.

http://www.setneg.go.id.

Kompas edisi tanggal 3 Februari 2010

Direktorat Pengawasan dan Pengendalian Mutu Barang Departemen Perdagangan (2005). Pemetaan Laboratorium penguji Mutu Produk Agro, Industri Agro, SNI Wajib dan LSPro.

Peraturan Menteri Perdagangan RI No 14/MDAG/PER/2007 Tentang Standardisasi Jasa Bidang Perdagangan dan Pengawasan Standar Nasional Indonesia (SNI) Wajib Terhadap Barang dan Jasa Yang Diperdagangkan.

Peraturan Pemerintah RI No 102 Tahun 2000 Tentang Standardisasi Nasional

BSN. (2007). Senarai Standar Nasional Indonesia-SNI.

(2007) Standar dan Perdagangan-SNI Valuasi (Majalah Standardisasi Nasional). 